\title{
The vitamin D content and consumer acceptability of vitamin D biofortified eggs
}

\author{
A. Hayes ${ }^{1}$, M. O’Grady ${ }^{1}$, S. Duffy ${ }^{2}$, K. Seamans ${ }^{1}$, J. Kerry ${ }^{1}$, Alan Kelly $^{2}$, J. Jakobsen ${ }^{3}$, \\ J. O'Doherty ${ }^{2}$ and K.D. Cashman ${ }^{1}$ \\ ${ }^{1}$ School of Food and Nutritional Sciences, University College Cork, Republic of Ireland, ${ }^{2}$ School of Agriculture and \\ Food Science, University College Dublin, Belfield, Dublin 4, Republic of Ireland and ${ }^{3}$ Division of Food Chemistry, \\ Technical University of Denmark, Demark
}

Biofortification of foods with vitamin D may offer an additional strategy to traditional fortification approaches as a means of bridging the gap between current vitamin D intakes and recent new recommendations. ${ }^{(1)}$ In the biofortification process, animal produce (such as, e.g., eggs, cultured fish, beef, pork, lamb, chicken) could have increased vitamin D and/or 25-hydroxyvitamin D (25(OH)D) contents by virtue of addition of vitamin $\mathrm{D}$ and/or 25 -hydroxyvitamin $\mathrm{D}\left(\mathrm{HyD}^{\circledR}\right.$; where permissible) to the livestock feeds. ${ }^{(2)}$ The aim of the present work was to examine the effect of additional vitamin $\mathrm{D}_{3}\left(\mathrm{D}_{3}\right)$ and/or $\mathrm{HyD}^{\circledR}$ in hen diets on total vitamin $\mathrm{D}$ activity of resulting eggs and to assess their consumer acceptability. Sixty laying hens (Hyline; $n$ 15/group) were allocated to one of the following experimental diets: basal diet plus either $1500 \mathrm{IU} \mathrm{D}_{3}$ (T1); $3000 \mathrm{IU} \mathrm{D}_{3}$ (T2); $1500 \mathrm{IU} \mathrm{D}_{3}+1500 \mathrm{IU} \mathrm{HyD}^{\circledR}$ (T3); or 3000 IU HyD ${ }^{\circledR}$ (T4) per kg diet for 6 weeks. The vitamin $\mathrm{D}_{3}$ and $25(\mathrm{OH}) \mathrm{D}$ content of pooled samples of egg yolks (at week 6) from each group were analysed in Demark using a sensitive liquid chromatography with tandem MS method. Following analysis, the total vitamin D activity was calculated as vitamin $\mathrm{D}_{3}$ plus $(25(\mathrm{OH}) \mathrm{D} \mathrm{X} 5){ }^{(3)}$ The total vitamin $\mathrm{D}$ activity (mean $\pm \mathrm{SD}$; two separate pooled samples on separate days during week 6 per treatment) of eggs from diets T1, T2, T3 and T4 was 2.9 $\pm 0 \cdot 6,3 \cdot 8 \pm 0 \cdot 3,4 \cdot 8 \pm 0 \cdot 4,5 \cdot 1 \pm 0 \cdot 8 \mu \mathrm{g} / \mathrm{egg}$, respectively.

Sensory evaluation of boiled and fried eggs was carried out in two separate sensory analysis sessions using 20 naïve assessors where four egg samples (one from each of T1 to T4), identified with random three digit codes, were presented to each panellist in duplicate. Sensory analysis was undertaken in the panel booths at the sensory laboratory in accordance with ISO (1988) international standard regulations. Hedonic (appearance, liking of flavour, liking of texture and overall acceptability) (dislike/like, unacceptable/acceptable) and intensity sensory analysis descriptors (yolk colour (yellow/orange), egg white (white/grey), sulphur flavour (none/extreme), sour (not/very), sweet (not/very), salty (not/very), odour (weak/strong) and off-flavour (none/extreme)) were determined. ANOVA-partial least squares regression (APLSR) of the sensory data using Unscrambler software (version 10.3) has shown no significant positive or negative correlations between dietary treatments and the sensory descriptors examined.

In conclusion, biofortification of eggs with vitamin $\mathrm{D}$ may be a useful additional approach for tackling low vitamin $\mathrm{D}$ intakes in the population. While addition (at the EU upper allowable levels) of $\mathrm{D}_{3}$ or a mix of $\mathrm{D}_{3}$ and $\mathrm{HyD}^{\circledR}$ to the hen diets increased total vitamin $\mathrm{D}$ activity of eggs, addition of $\mathrm{HyD}^{\circledR}$ alone to the hen diet (at the EU upper allowable level) produced the highest total vitamin $\mathrm{D}$ activity in eggs. All the vitamin D-enhanced eggs were of equal acceptability to consumers.

The project was funded by the Irish Department of Agriculture and Food's Food Institutional Research Measure (FIRM), funded under the National Development Plan 2007-2013.

1. Institute of Medicine (2011) Dietary Reference Intakes for Calcium and Vitamin D. Washington DC: National Academy Press.

2. Cashman KD (2015) J Steroid Biochem Mol Biol. (in press).

3. Cashman KD, Seamans KM, Lucey AL et al. (2012) Am J Clin Nutr. 95, 1350-6. 